\title{
Formation of noncanonical high molecular weight caspase- 3 and -6 complexes and activation of caspase-12 during serum starvation induced apoptosis in AKR-2B mouse fibroblasts
}

\author{
M Kilic ${ }^{1,3}$, R Schäfer ${ }^{1,2,3}$, J Hoppe ${ }^{\star, 1}$ and U Kagerhuber ${ }^{1}$ \\ 1 Department of Physiological Chemistry, University of Würzburg, Germany \\ ${ }^{2}$ Current address: Xantos Biomedicine GmbH, Martinsried, Germany \\ ${ }^{3}$ Mehtap Kilic and Rolf Schäfer contributed to this work equally \\ * Corresponding author: J Hoppe, Biozentrum, Department of Physiological \\ Chemistry, University of Würzburg, Am Hubland, 97074 Würzburg, Germany. \\ Tel: 49931888 41 13; Fax: 4993188841 13; \\ E-mail: hoppe@biozentrum.uni-wuerzburg.de
}

Received 10.1.01; revised 11.6.01; accepted 27.6.01

Edited by $S$ Martin

\begin{abstract}
Apoptosis is mainly brought about by the activation of caspases, a protease family with unique substrate selectivity. In mammals, different complexes like the DISC complex or the apoptosome complexes have been delineated leading to the cleavage and thus activation of the executioner caspases. Although caspase- 3 is the main executioner caspase in apoptosis induced by serum starvation in AKR-2B fibroblasts as demonstrated by affinity labeling with YVK(-bio)D.aomk and partial purification of cytosolic extracts by high performance ion exchange chromatography, its activation is apparently caused by a noncanonical pathway: (1) Expression of CrmA, an inhibitor of caspase-8, failed to suppress apoptosis; (2) There was no formation of high molecular weight complexes of Apaf-1 indicative for its activation. Furthermore no cleavage of caspase-9 was observed. But surprisingly, gelfiltration experiments revealed the distribution of caspase- 3 and -6 into differently sized high molecular weight complexes during apoptosis. Though the apparent molecular weights of the complexes containing caspase-3 (600 kD for apoptosome and $250 \mathrm{kD}$ for microapoptosome) are in accordance with recently published data, the activity profiles differ strikingly. In AKR-2B cells caspase-3 is mainly recovered as uncomplexed enzyme and in much lower levels in the apoptosomes. Remarkably, the $600 \mathrm{kD}$ and $250 \mathrm{kD}$ complexes containing activated caspase- 3 were devoid of Apaf-1 and cytochrome $c$. In addition a new 450 kD complex containing activated caspase- 6 was found that is clearly separated from the caspase- 3 containing complexes. Furthermore, we disclose for the first time the activation of caspase-12 in response to serum starvation. Activated caspase-12 is detectable as non-complexed free enzyme in the cytosol. Cell Death and Differentiation (2002) 9, 125-137. DOI: 10.1038/ sj/cdd/4400968
\end{abstract}

Keywords: caspases; apoptosis; fibroblasts

Abbreviations: DISC, death-inducing signaling complex; AIF, apoptosis inducing factor; Apaf-1, apoptosis protease activating factor; 7-AAD, 7-amino-actinomycin D; DEVD.pNA, asp-glu-valasp-paranitroanilide; DEVD.cho, asp-glu-val-asp-aldehyde; VEID.pNA, val-glu-ile-asp-paranitroanilide; VEID.cho, val-glu-ileasp-aldehyde; IETD.pNA, ile-glu-thr-asp-paranitroanilide; IETD.cho, ile-glu-thr-asp-aldehyde; LEHD.pNA, leu-glu-his-asp-paranitroanilide; LEHD.cho, leu-glu-his-asp-aldehyde; YVK(-bio)D.aomk, tyr-val-(biotinyl)|lys-asp-aryloxymethylketone; GFP, green fluorescent protein; FACS, fluorescence activated cell sorter; HRPO, horseradish peroxidase; cyt $c$, cytochrome $c$

\section{Introduction}

Selective cell death has an extraordinary function during development and homeostasis of tissues. The identification of the genetic regulation of apoptosis, of its orderly phenotypes, and of its essential role has led to the current concept that the majority of cells can only survive in the presence of appropriate growth or survival factors. In all cases that have been studied to date, apoptosis is regulated by signals in form of cell lineage information, of soluble mediators, or of cell-tocell contact. Withdrawal of these signals leads to selective cell death by apoptosis.

This physiological cell death appears in many facets, but certain biochemical and morphological hallmarks, like chromatin condensation, DNA fragmentation and specific cleavage of proteins, are recurrent (for review see ${ }^{1-11}$ ). Particularly the latter is believed to be due to the activity of cysteine proteases, called caspases. The emerging evidence suggests that during apoptosis diverse regulatory pathways activate a common execution machinery, which carries out cell disassembly. Although this machinery is not yet completely understood, it is clear that essential components are these cysteine proteases. Due to their substrate specificity and their propagated role in apoptosis, the caspase family can be divided into three functional groups, the inflammatory caspases (casp-1, $-4,-5,-11,-13$, -14), the initiator caspases (casp-2, -8, -9, -10, -12) and effector caspases (casp-3, -6, -7). ${ }^{12-15}$ The activation of effector caspases, i.e. caspase- $3,-6$ or -7 is a crucial step and marks a point of no return. ${ }^{13,16,17}$

Up to now three plausible pathways for the cleavage and thus activation of the executioner caspases have been delineated: (1) A receptor mediated recruitment of caspase8 into the DISC-complex, which is composed by receptors, adapter proteins and caspase-8 leading to its auto- 
activation followed by a cleavage of the effector caspases$3,-6$ and $-7 . .^{18-21}$ (2) Alternatively, proapoptotic proteins are released from mitochondria, ${ }^{20,22,23}$ like a $50 \mathrm{kD}$ protein (AIF) that by itself suffices to cause nuclear apoptosis ${ }^{24,25}$ and the $15 \mathrm{kD}$ cytochrome $c$ protein which together with a cytosolic factor termed Apaf-1, dATP and caspase-9 forms a multimeric complex, termed apoptosome, leading to the activation of the bound executioner caspase. The activated caspase is then released to a smaller multimeric complex, the microapoptosome. ${ }^{26}$ (3) Caspase-12 bound to the endoplasmatic reticulum (ER) is activated by ER stress leading to a subsequent cleavage of caspase-3. ${ }^{27}$

High molecular complexes seem to organize the localization of caspases and may not only regulate the activation of initiator caspases but also that of effector caspases. $^{28}$

Density arrested AKR-2B fibroblasts die rapidly after serum deprivation. ${ }^{29,30}$ Morphological changes include membrane blebbing and chromatin condensation, but remarkably there is no DNA fragmentation. Apoptosis is abolished by the caspase inhibitors YVAD.cmk, ${ }^{30}$ DEVD. cho or Z-DEVD.cmk. ${ }^{31}$ Multiple signaling pathways, which interfere with the activation of a caspase-3 like activity, have been identified. ${ }^{29,31,32}$

Here we show that although all caspases are expressed in AKR-2B cells, caspase-3 is the main executioner caspase; caspase-7 protein is not detectable. Furthermore, we demonstrated the formation of three different sized complexes in response to serum deprivation. The $600 \mathrm{kD}$ and a $250 \mathrm{kD}$ multimeric apoptosome like complexes contain activated caspase-3, but are devoid of Apaf- 1 and cytochrome $c$. In addition, we describe a new $450 \mathrm{kD}$ complex where active caspase- 6 is detectable. Moreover, the activation of caspase-12 by serum starvation is disclosed.

\section{Results}

\section{Serum starvation of AKR-2B cells induce the activation of caspases}

Apoptotic cell death of AKR-2B fibroblasts in response to serum starvation was demonstrated in earlier publications. ${ }^{29}$ After 3 h serum starvation $20-30 \%$ of cells undergo apoptotic cell death reaching a plateau of $50 \%$ surviving cells after $6 \mathrm{~h} .{ }^{30}$ The aim of this study was to characterize the process of caspase activation in these cells. First, the expression pattern of caspases in non-starved cells was determined by Riboquant assay (Pharmingen) using a commercial available template set and a self-constructed probe for caspase-9, respectively (Figure 1). The mRNA of all analyzed caspases could be detected with the exception of caspase-14.

Next the activation of caspases during serum starvation was studied by enzymatic assays. Caspase activities were maximal $3 \mathrm{~h}$ after onset of apoptosis, as determined by photometric assays using cytosolic extracts of AKR-2B fibroblasts (Figure 2A). Cytosolic extracts of non-starved AKR-2B showed very little DEVDase activity, which increased 18-fold to maximum activity after $3 \mathrm{~h}$ of serum starvation and returned to base level after $8 \mathrm{~h}$. DEVDase

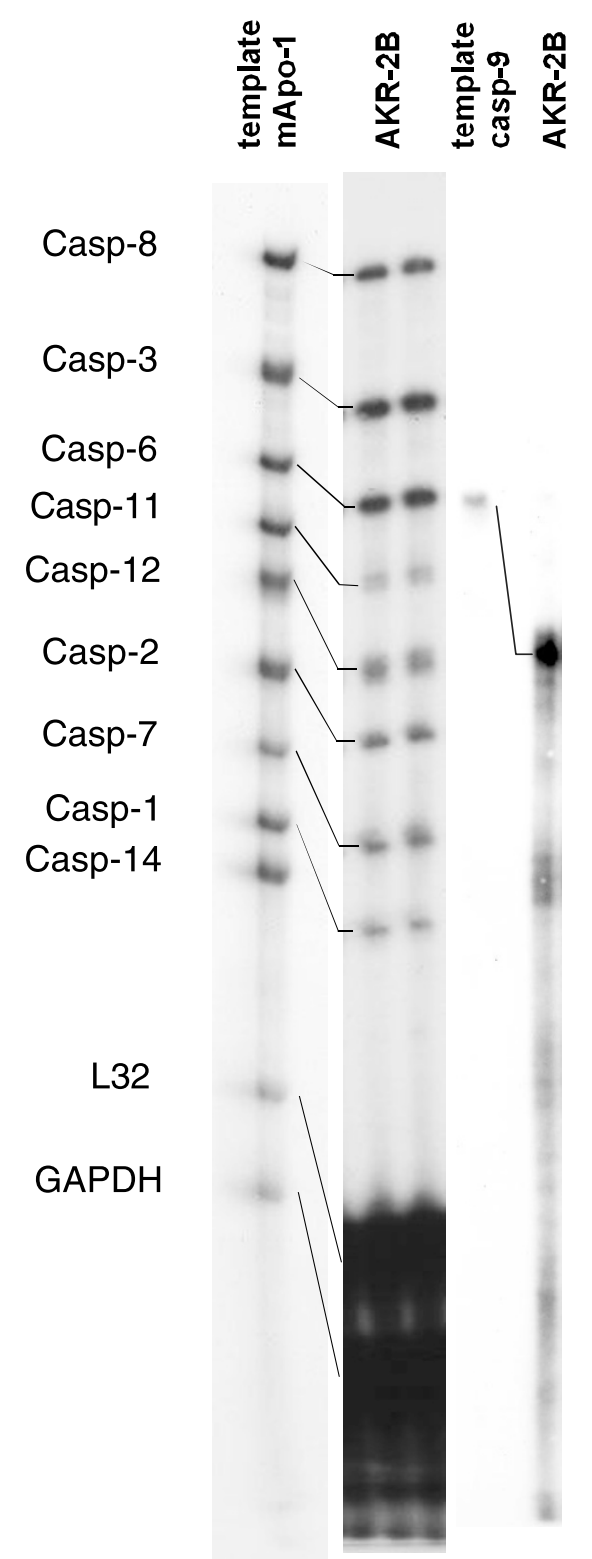

Figure 1 Analysis of mRNA expression of caspases in AKR-2B cells. Total RNA of non starved AKR-2B cells was hybridized with DNA-probes from Pharmingen (mApo-1) and a probe for caspase-9, prepared as described under Material and Methods. Nuclease protection assay was performed according to manufacturer's instructions

activity was completely suppressed by the inhibitor DEVD.cho, indicating that the activity was due to an activated caspase (presumably caspase-3). We observed substantial basal VEIDase, IETDase and LEHDase activities that were only partially suppressed by the respective inhibitors VEID.cho, IETD.cho or LEHD.cho, respectively. IETDase and LEHDase activities were only slightly increased after $3 \mathrm{~h}$ of serum deprivation (1.5-fold and 1.8fold, respectively). The VEIDase showed a higher maximal (threefold increased) activity after $3 \mathrm{~h}$ of starvation, but this activity was only partially suppressed by $1 \mu \mathrm{M}$ VEID.cho. 
Though YVAD.cmk has been shown to inhibit apoptosis of AKR-2B fibroblasts, ${ }^{30}$ no endogenous YVAD activity was detectable in response to serum starvation. ${ }^{31}$ Whereas the activation of a DEVDase is quite evident and is likely due to the activation of caspase-3 or -7, the assignment of the VEIDase activity to an activated caspase- 6 is ambiguous, since recombinant caspase- 3 exhibits a considerable VEID.pNA cleavage activity (about $30 \%$ of that of DEVD.pNA). The activities were further characterized by determining their respective $\mathrm{K}_{\mathrm{m}}$ - or $\mathrm{K}_{\mathrm{i}}$ - values. Untypical high $\mathrm{K}_{\mathrm{M}}$-values compared to the literature for DEVD (recombinant caspase-3: $14 \mu \mathrm{M}$ ), VEID (recombinant caspase-6: $35 \mu \mathrm{M}$ ) and IETDase (recombinant caspase-8: $40 \mu \mathrm{M})$ were found as illustrated in Table 1.

\section{The main active executioner caspase in AKR-2B fibroblasts is caspase- 3}

To further define activated caspases we applied the affinity label YVK(-bio)D.aomk which is reported to specifically label the executioner caspase-3, -6 and $-2 .^{33}$ First the inhibition profile of YVK(-bio)D.aomk in the presence of various substrates was determined. The DEVDase activity was completely inhibited, whereas VEIDase and IETDase activities are only partially decreased (down to $50 \%$ and $70 \%$, respectively, Figure $2 \mathrm{~B}$ ). These data are in line with the above observation of constitutive VEIDase and IETDase activities, which were not inhibited by specific caspase inhibitors. 2Dgelelectrophoresis showed a rather simple spot pattern for affinity labeling with YVK(-bio)D.aomk which was identical to the pattern obtained by staining with a caspase-3-p17 antibody (Figure $2 \mathrm{C}$ ), confirming that the caspase activity in AKR-2B fibroblasts is mainly due to caspase-3. Because DEVD.pNA is a substrate for both caspase-3 and -7, we further analyzed caspase-7 in Western blotting. As illustrated in Figure 3B caspase-7 protein is not detectable in AKR-2B compared to Jurkat cells lysates, although caspase-7 mRNA is expressed (see Figure 1).

Caspase activities were partially purified by anionic exchange chromatography using a Resource $Q$ column. In those fractions showing caspase activity (Figure 3A, middle) only the active p17 subunit of caspase-3 was found and affinity labeling with YVK(-bio)D.aomk was exclusively detected in these fractions (Figure $3 A$, top). The zymogens of caspase-1, $-2,-3,-6$ and -12 as well as a cleavage product of caspase-12 (around $40 \mathrm{kD}$ ) eluted separately. Furthermore the activity profile associated with the peak eluting during the salt gradient is identical with that reported for recombinant caspase-3 (unpublished data). Remarkably no tetrapeptide cleavage activity was found in those fractions containing cleaved (activated) caspase-12.

\section{Serum starvation of AKR-2B cells results in caspase-activities localized to different molecular weights ( $\sim 600 \mathrm{kD}, \sim 250 \mathrm{kD}$ and $\sim 60 \mathrm{kD}$ )}

To further characterize the DEVDase activity and to detect apoptosome complexes in our system, we used size exclusion chromatography to fractionate cytosolic extracts from both non-starved (=control) and $3 \mathrm{~h}$ starved (=apoptotic)
AKR-2B cells. In contrast to Cain et $a l,{ }^{26}$ when an apoptotic extract from AKR-2B was separated by Sephacryl $\$ 300$ column, DEVDase eluted mainly as uncomplexed enzyme around $60 \mathrm{kD}$ and in a lesser extent complexed at $>700 \mathrm{kD}$, $600 \mathrm{kD}$ and $250 \mathrm{kD}$, respectively (Figure 4A, bottom). By use of a specific peptide inhibitor for the DEVDase activity (DEVD.cho) it is shown, that the high molecular activity of $>700 \mathrm{kD}$ was not inhibitable (Figure 4B, top), indicating unspecific activity. In contrast, DEVD.cho inhibited the activities in the other fractions. Using a Superose $6 \mathrm{HR}$ column for a better resolution of the high molecular weight region these DEVDase activities appear to elute in a broad region from $>2000 \mathrm{kD}$ to $700 \mathrm{kD}$ (Figure 6A) and the DEVDase activity is not inhibitable by its peptide inhibitor in the very high molecular range $>1 \mathrm{MDa}$ (data not shown). VEIDase eluted as a broad peak from $>700 \mathrm{kD}$ (Figure 4A), again eluting as a broad peak from $>2000 \mathrm{kD}$ to $700 \mathrm{kD}$ by using Superose $6 \mathrm{HR}$ column (Figure 6A), down to $450 \mathrm{kD}$ and as uncomplexed enzyme at $45 \mathrm{kD}$ (Figure 4A). Unexpectedly, the VEIDase at $>2000 \mathrm{kD}$ to $600 \mathrm{kD}$ was higher compared to the DEVDase activity. Again the activity $>2000 \mathrm{kD}$ was not inhibitable using the specific inhibitor VEID.cho (Figure 4B, middle). In addition, gelfiltration of control extracts showed VEIDase activity in the region $>2000 \mathrm{kD}$ (Figure 4A and 6A top), which was also not inhibitable by its specific inhibitors (data not shown), confirming unspecific protease activities. The additional activity peaks at $600 \mathrm{kD}$ in control lysates, can be explained by constitutive caspase activities in this high molecular complex. Also IETDase activity which eluted in the expected fractions containing the $>2000 \mathrm{kD}$ complex was not inhibitable by its specific inhibitor (IETD.cho).

Thus, specific DEVDase activity was mainly found as uncomplexed enzyme and in lesser extent in the apoptosome of $600 \mathrm{kD}$ molecular weight and the microapoptosome of $250 \mathrm{kD}$, respectively. Specific VEIDase eluted mainly with the apoptosome and with lower activities as uncomplexed enzyme.

\section{Active caspase- 3 and caspase- 6 are localized to different complexes in apoptosis}

The gelfiltration results presented above strongly suggest the existence of different multimeric complexes, which are involved in caspase activation. To further characterize these complexes, Sephacryl S300 column fraction were analyzed by SDS-PAGE and Western blotting. In control extracts of non starved cells zymogens of both caspase- 3 and caspase- 6 eluted as free enzymes (Figure 5A). Caspase-3 zymogene additionally appeared in the high molecular region (Figure 5A) and was localized to $>2000 \mathrm{kD}$ by using a Superose $6 \mathrm{HR}$ column (Figure 6B). The active subunits of caspase- 3 and -6 are not detectable in any fraction, indicating that caspases are not processed in non starved AKR-2B. In fractions from extracts of apoptotic cells the zymogens still eluted as uncomplexed enzymes. The subunit p17 of activated caspase-3 was detectable mainly as uncomplexed enzyme in accordance to the DEVDase activity profile and in a lesser extent in the $250 \mathrm{kD}$ microapoptosome and in the $600 \mathrm{kD}$ apoptosome, respectively. In contrast, active caspase-6p12 
eluted at $450 \mathrm{kD}$ and as free enzyme. Surprisingly, activated caspase- 6 as detected by Western blotting did not co-elute with the major VEID-activity in the high molecular weight range $(>450 \mathrm{kD}$ ) (Figures $4 \mathrm{~A}$ and $5 \mathrm{~A}$ ), though this activity was inhibited by the compound VEID.cho. Furthermore, there was only marginal VEIDase activity in those fraction which revealed the presence of cleaved (activated) caspase-3. The assessment of a VEIDase activity in the low molecular weight range is compromised by the presence of caspase-3, which exhibits a considerable activity towards the substrate VEID.pNa. To demonstrate caspase- 6 activity Western blotting directed against its specific substrates - the lamins $(A / C$ and $B)$ - were performed, showing their cleavage in response to serum starvation (Figure $5 \mathrm{~B}$ ). This cleavage was prevented by the addition of the specific inhibitor Z-VEID.fmk (Figure 5B lower panel). Thus an activation of caspase-6 was evident by gelchromatographie in combination with Western blotting which was supported by the in vivo cleavage of lamins.

To elucidate, if the found complexes are similar to the known (micro-)apoptosome, ${ }^{26,34}$ we analyzed the distribution of Apaf-1, cytochrome $c$ (cyt $c$ ) and caspase- 9 by Western blotting. Surprisingly, apoptosis in AKR-2B cells did not induce the complex formation of Apaf-1, caspase- 9 and cytochrome $c$ (Figures 5A and 6). Apaf-1 and caspase-9 still eluted in the same fractions most likely as mono-/dimers and cyt $c$ as uncomplexed protein compared to non-starved cells. In addition, only the inactive zymogene of caspase-9 was detectable in Western blotting. In contrast to the in vivo situation (serum starvation), the addition of $200 \mu \mathrm{g}$ cyt $c$, $2 \mathrm{mM}$ dATP and $5 \mathrm{mM} \mathrm{MgCl}_{2}$ (Figure 7) to untreated cytosolic extracts resulted in the distribution of a considerable fraction of Apaf- 1 into the 1.4 MDa complex, though the major part still eluted in the mono-/dimer region. In contrast, in THP-

A

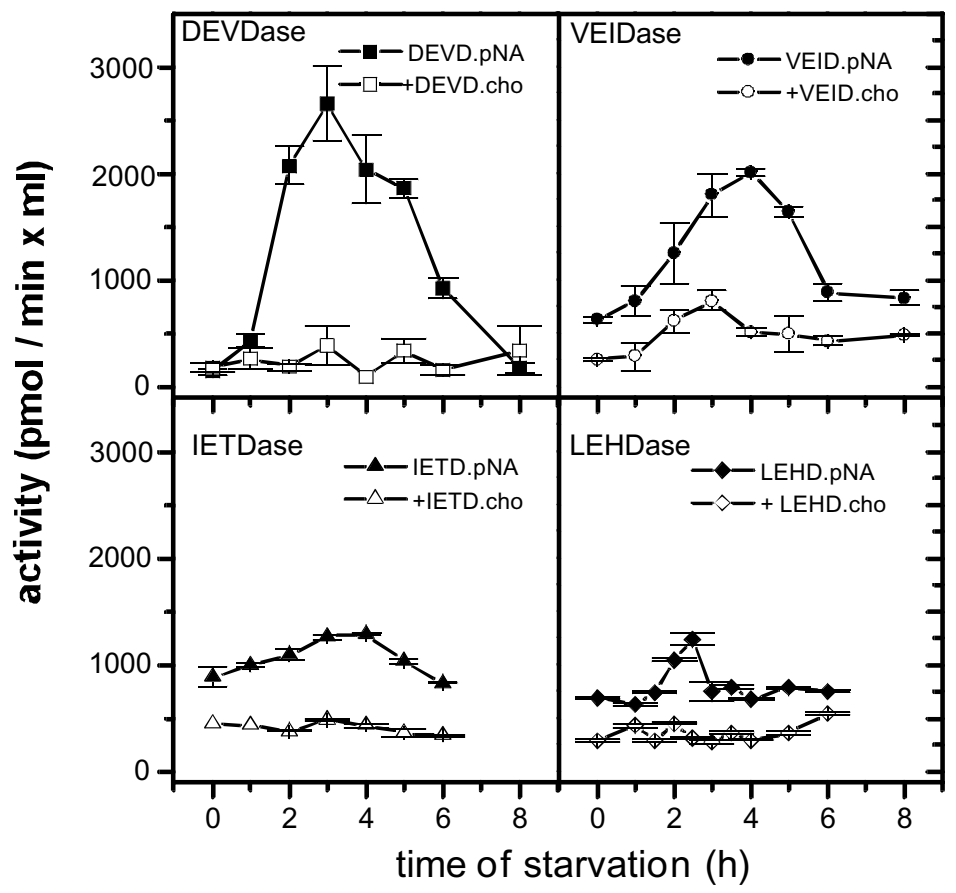

$\mathrm{B}$

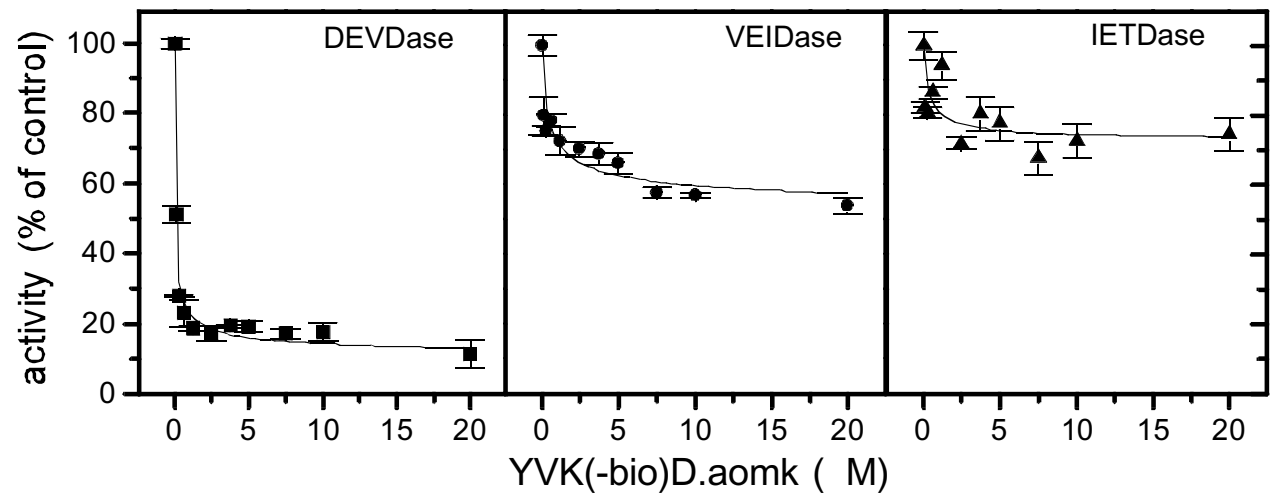


1 cells most of Apaf- 1 is detected in the $700 \mathrm{kD}$-apoptosome (Figure 7), to a lesser content in the mono-/dimer region and in the 1.4 MDa complex. Additionally, the in vitro complex formation was accompanied by differences in the DEVDase activity profiles. In THP-1 cells DEVDase eluted mainly as a sharp single peak in the free enzyme region, whereas in AKR$2 \mathrm{~B}$ fibroblasts the major part of the activity eluted in the fractions corresponding to apoptosome complexes (200 kD and $700 \mathrm{kD}$ ) (Figure 7 upper panel).

Thus, the active subunits of caspase- 3 and -6 were detected in different complexes. Caspase-3-p17 eluted in the apoptosome like $600 \mathrm{kD}$ - and $250 \mathrm{kD}$-complexes, which seems to be composed differently from known described (micro-)apoptosomes. Furthermore, active caspase-6-p12 was found in a distinct, to our knowledge new complex of $450 \mathrm{kD}$.

\section{The proteasome coelutes with $\sim 2$ MDa unspecific VEID/IETDase activities}

Recently, the coelution of the proteasome complex with VEIDase and IETDase activity was demonstrated. ${ }^{26}$ To analyze if unspecific VEID/IETDase activities in our system are also coeluting with the proteasome, Western blotting with an antibody directed against the 20S-proteasome $\alpha$-subunit was performed. In control cells this proteasome-subunit

Table 1 Enzyme kinetics of caspases

\begin{tabular}{lcccc}
\hline & $\mathbf{K}_{\mathbf{M}}$-values & \multicolumn{3}{c}{$\mathbf{K}_{\mathbf{i}}$-values [nM] } \\
& {$[\mu \mathbf{M}]$} & DEVD.cho & VEID.cho & IETD.cho \\
\hline DEVD.pNa & $79 \pm 18$ & $1.7 \pm 0.5$ & $76.6 \pm 15$ & $125.8 \pm 5.6$ \\
VEID.pNa & $236 \pm 78$ & $63 \pm 25$ & $73.2 \pm 18.3$ & $243 \pm 16$ \\
IETD.pNa & $509 \pm 133$ & $48 \pm 7.2$ & $49 \pm 11$ & $54 \pm 12$ \\
\hline
\end{tabular}

To determine $\mathrm{K}_{\mathrm{M}}$-values $75 \mu \mathrm{g}$ protein of cytosolic extracts from AKR-2B cells $(3 \mathrm{~h}$ starved) were incubated with increasing concentrations of indicated substrates. Cleaving activity was detemined photometrically. The data were analyzed by a non-linear dihyperbolic regression using the program Origin $4.1^{\mathrm{TM}}$. For determination of $\mathrm{K}_{\mathrm{i}}$-values $75 \mu \mathrm{g}$ protein of apoptotoc cytosolic extract was incubated with $150 \mu \mathrm{M}$ of the indicated substrates (DEVD.pNA, VEID.pNA, IETD.pNA) in combination with increasing amount of the indicated inhibitors (DEVD.cho, VEID.cho OR IETD.cho) and cleaving activity was determined. $\mathrm{K}_{\mathrm{i}}$ values were calculated by using the formula $x_{0}=-K_{i}\left(1+[S] / K_{M}\right)$ described by 44
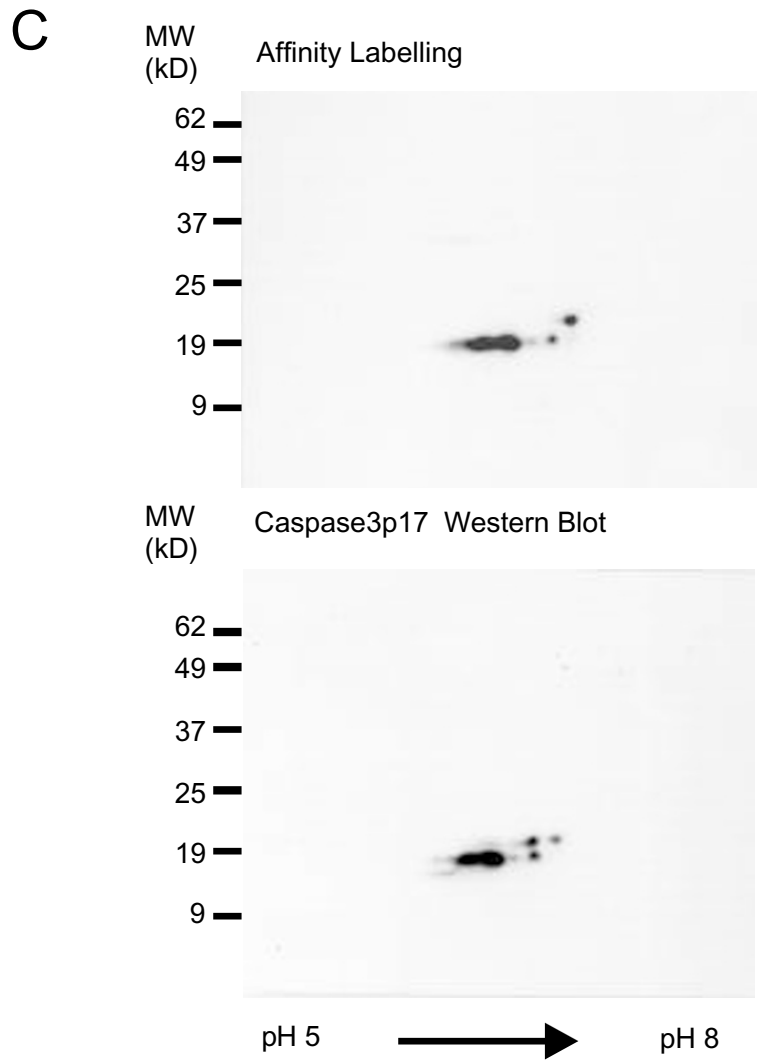

Figure 2 Characterization of caspase activities. (A) Kinetic of caspase activation in AKR-2B cells. AKR-2B cells were grown and starved for indicated time intervals as described. To determine cleaving activities, $75 \mu \mathrm{g}$ protein of cytosolic extract was incubated with the respective caspase substrates (DEVD.pNA $(100 \mu \mathrm{M}, \mathbf{\square})$, VEID.pNA $(300 \mu \mathrm{M}, \mathbf{0})$, IETD.pNA $(300 \mu \mathrm{M}, \boldsymbol{\Delta})$, LEHD.pNA $(300 \mu \mathrm{M}$, $\bullet)$. Background activities were measured by adding $1 \mu \mathrm{M}$ of the specific inhibitors to the respective reaction mixtures (DEVD.cho $\square$, VEID.cho $O$, IETD.cho $\triangle$, LEHD.cho $\diamond$ ). (B) Inhibition of caspase activities by the covalently binding compound YVK(-bio)D.aomk. As above $75 \mu \mathrm{g}$ protein of cytosolic extract was incubated with the respective caspase substrates (DEVD.pNA (100 $\mu \mathrm{M}$, 口), VEID.pNA $(300 \mu \mathrm{M}, \mathbf{0})$ or IETD.pNA $(300 \mu \mathrm{M}, \mathbf{\Lambda})$ in the presence of increasing amounts of YVK(-bio)D.aomk. Data were fitted by a logistical regression analysis using the program Origine $4.1^{1}$ (Microcal). (C) $2 \mathrm{D}$-electrophoresis. $500 \mu \mathrm{g}$ of apoptotic cytosolic extract of AKR-2B cells was incubated with $10 \mu \mathrm{M}$ of the biotinylated caspase inhibitor YVK(-bio)D.aomk and proteins were separated by 2D-gelelectrophoresis as described in Materials and Methods. After transferring on PVDF membranes caspase-3-p17 was detected by the antibody against the processed caspases-3 and labeling (YVK(-bio)D.aomk) by extravidin-HRP 
A

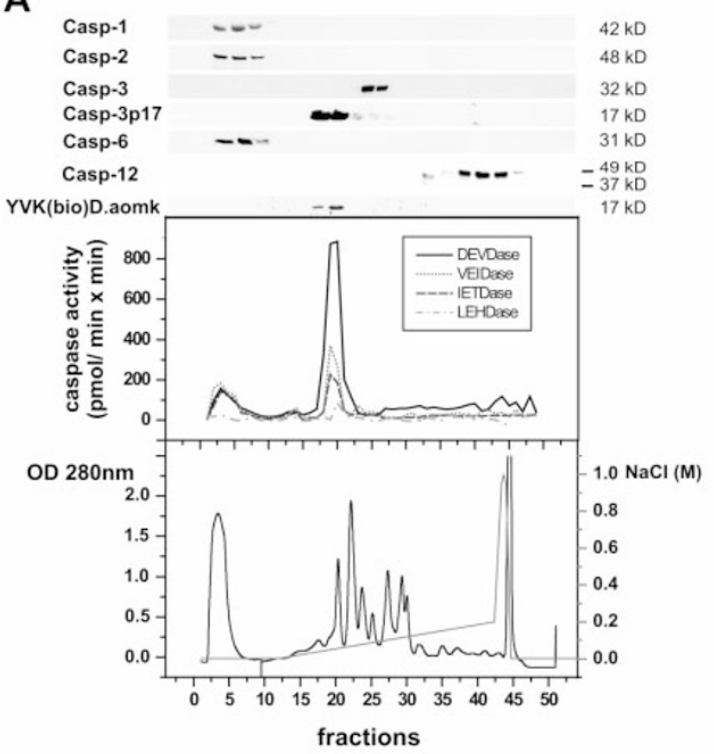

B

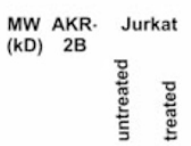

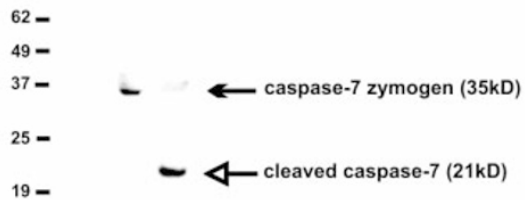

Figure 3 Caspase-3 is the dominant active caspase in AKR-2B fibroblasts (A) Five mg protein of an apoptotic cytosolic extract of AKR-2B cells was separated on an anionic exchange column as described in Materials and Methods $\left(\mathrm{OD}_{280}\right.$-trace and salt gradient are shown in the lower panel). The fractions were analyzed for caspase activity by the use of indicated caspase substrates $(100 \mu \mathrm{M}$ of DEVD.pNA and $200 \mu \mathrm{M}$ of VEID.pNA, IETD.pNA and LEHD.pNA) (middle panel). The distribution of caspases within the fraction was analyzed by Western blotting of lyophilized fractions using specific antibodies for caspases $-1,-2,-6$ and -12 detecting both the zymogene and the activated cleaved form. The antibodies used for caspase- 3 detect either the zymogene p32 or the activated p17 subunit of that enzyme, respectively. Additionally, all fractions were supplemented with $10 \mu \mathrm{M}$ of the biotinylated caspase inhibitor YVK(-bio)D.aomk prior to lyophilization and labeling was analyzed by blotting followed by the incubation with extravidin-HRPO. (B) To analyze the expression of caspase-7 in AKR-2B cells Western blotting was performed by using an antibody directed against caspase-7. This antibody recognizes zymogene as well as cleaved casp-7. As a control, untreated or cytochrome $c$ treated Jurkat cell lysates were used, showing the absence of caspase-7 in AKR-2B

eluted mainly in a range corresponding to a molecular weight of $200-440 \mathrm{kD}$, most likely representing precursor proteasome complexes, ${ }^{35}$ additionally to a lesser extent in the region of $25-100 \mathrm{kD}$ most likely representing single subunits. Trace amounts were found in the high molecular weight region around $2 \mathrm{MDa}$ (Figure 6B, top). In response to $3 \mathrm{~h}$ serum starvation the 20S-proteasome precursor complexes around $300 \mathrm{kD}$ were still detected but there was a considerable increase in the fractions corresponding to $\sim 2 \mathrm{MDa}$ (most likely representing the catalytically active S26-proteasome complexes. ${ }^{35}$ ) Possibly a part of VEIDase- or IETDase activity, respectively, found in the high molecular weight region could be due to the presence of active proteasomes. Interestingly this fraction was clearly separated from the apoptosome. (Figure 6B).

\section{Caspase-12 is activated by serum starvation}

Caspase-12 has been reported to be activated by endoplasmatic stress. ${ }^{27}$ Here, we demonstrate the activation of caspase- 12 by serum starvation in embryonic fibroblasts. In control cytosolic extracts of non starved cells the zymogene of caspase-12 with a molecular weight of $48 \mathrm{kD}$ eluted at very high molecular weight region (Figure $5 \mathrm{C}$ ). Further analyses using the Superose $6 \mathrm{HR}$ column localized caspase-12 zymogene to $>2000 \mathrm{kD}$ (Figure 6B). No zymogene was detected in the microapoptosome complexes $(250 \mathrm{kd})$. Caspase-12 seems to be activated at very low levels in nonstarved cells, eluting from the column as uncomplexed enzyme. In response to serum starvation caspase-12 is completely cleaved into distinct fragments as double bands of around $35 \mathrm{kD}$ and $20 \mathrm{kD}$, respectively and released as free enzyme (Figures 5C and 6B). Unprocessed caspase-12 is not detectable any more.

Thus, we demonstrated the processing of caspase-12 in response to serum deprivation in embryonic fibroblasts resulting in various cleavage products.

\section{Receptor-induced apoptosis mediated by caspase-8 is not involved}

To examine the involvement of the receptor-induced apoptosis, mainly mediated by caspase-8, CrmA the inhibitor of caspase-8 was overexpressed in AKR-2B fibroblasts (Figure 8). The overexpression of a CrmA-GFP fusion protein (Figure $8 \mathrm{~A}$ ) or of CrmA cloned into pIRES expression vector (Figure 8B) does not prevent serum starvation (in combination with $10 \mu \mathrm{M}$ anisomycin) induced apoptosis. Figure 8A shows apoptotic cells illustrated as phase contrast and fluorescent photographs, Figure $8 \mathrm{~B}$ the cell loss of non-transfected compared to CrmA transfected AKR-2B sorted by FACS. Thus, apoptosis in response to serum starvation seems not to include the activation of caspase- 8 and the following proteolytic caspase cascade.

\section{Discussion}

In previous articles the basic features of the death process of AKR-2B cells after serum deprivation were described. ${ }^{30,31}$ In brief, most characteristic features of apoptosis are present: cells round up, membrane blebs appeared and nuclei condensed. But remarkably no DNA fragmentation and no ingestion of the dead cell by its neighbors occurred. After serum deprivation a caspase-3 like protease is activated, the activation of which is prevented via different intracellular pathways. Besides PDGF-BB and okadaic acid, ${ }^{29}$ forskolin, 8-Br-cAMP, colchicine and TPA were effective suppressors of protease activation and strongly promoted cell survival. ${ }^{31}$ 
A.

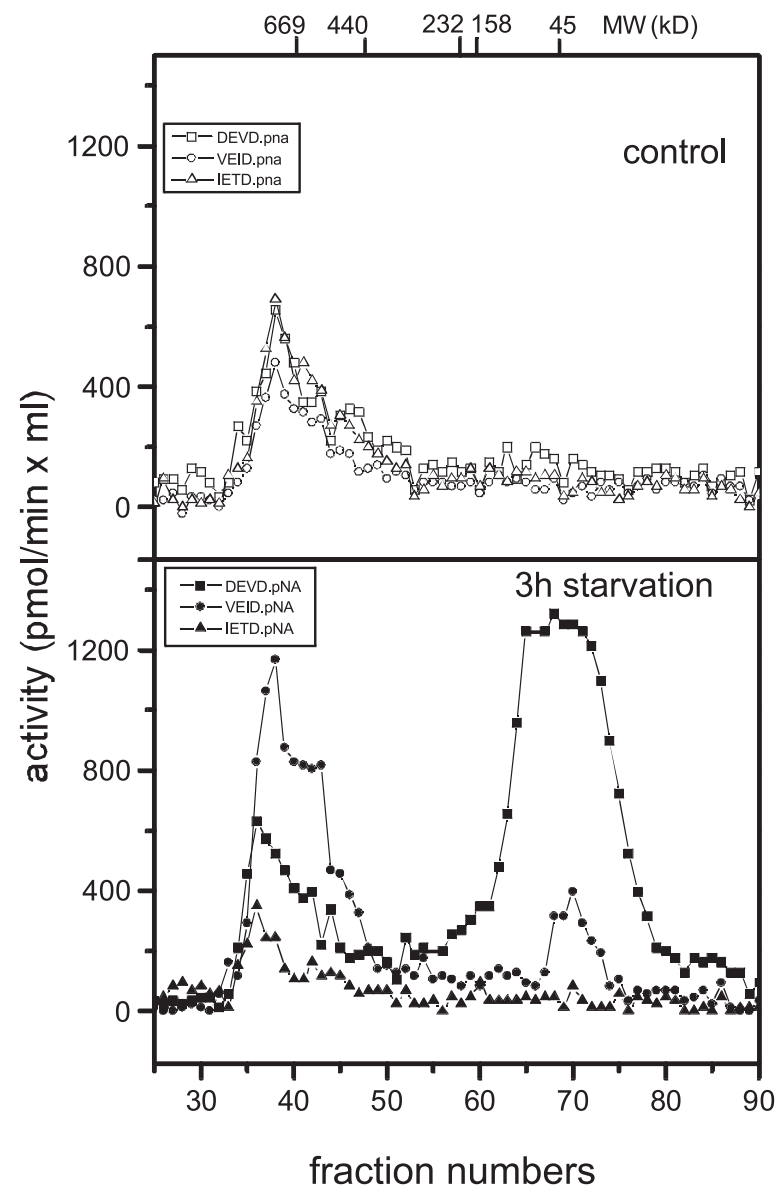

B.

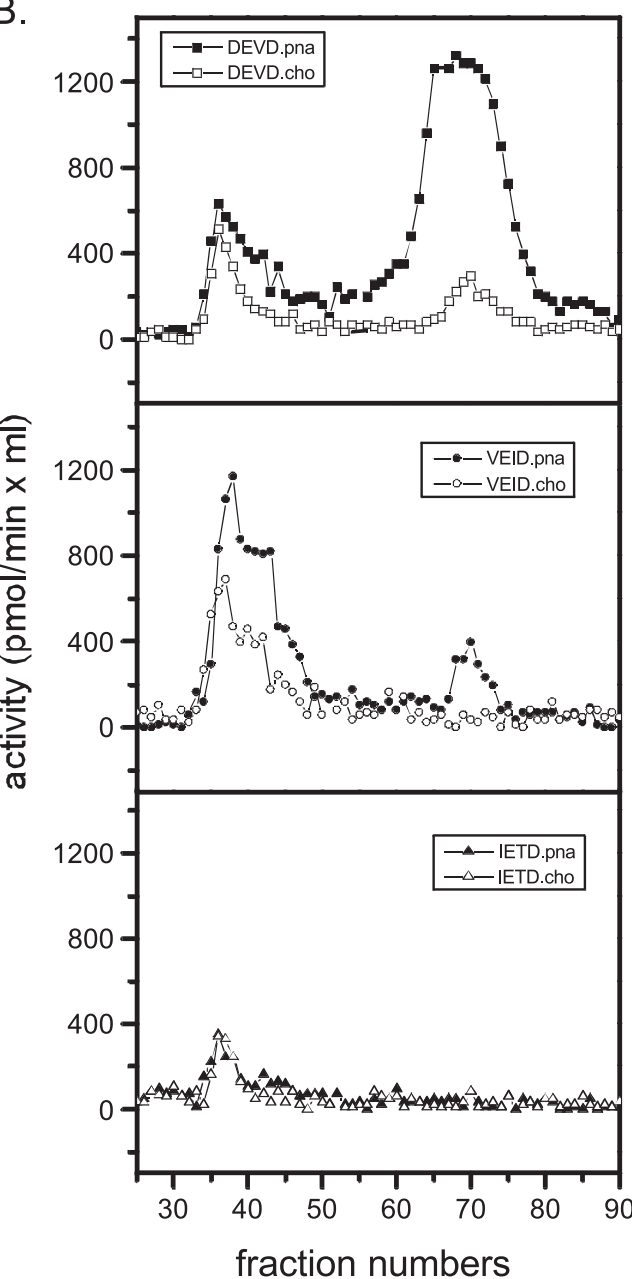

Figure 4 Caspase activities are found in different complexes. (A) Thirty mg protein of cytosolic extracts from control cells (upper panel) or serum-starved cells (lower panel) was separated by gelfiltration using a Sephacryl S300-HR column. Fractions of $1 \mathrm{ml}$ were collected. The first $24 \mathrm{ml}$ were discarded. To determine

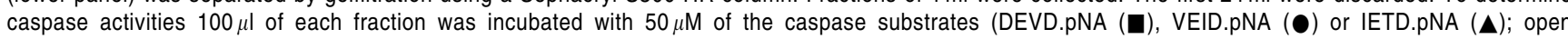
symbols=control, closed symbols $=3 \mathrm{~h}$ starved), as described under Materials and Methods. (B) To determine the specific caspase activities $100 \mu \mathrm{l}$ of the fractions was incubated with a caspase substrate (closed symbols) together with its specific inhibitor (100 nM DEVD.cho $\square, 500 \mathrm{nM}$ VEID.cho $\bigcirc$ or $500 \mathrm{nM}$ IETD.cho $\triangle$ respectively)

Here we demonstrate that caspase activities are maximal $3 \mathrm{~h}$ after onset of apoptosis. DEVDase is the main caspase activity with an 18 -fold increase in activity in response to serum removal. Purification of the DEVDase by anionic exchange chromatography as well as by using 2-D gelelectrophoresis revealed that caspase- 3 is the main active executioner caspase in AKR-2B cells. Caspase-7 protein is not detectable although its mRNA is expressed like all other caspases as confirmed by Riboquant assay. Activated caspase- 6 was only detected by Western blotting after gel-chromatography. As an indirect evidence for an activation of caspase- 6 the cleavage of lamins was demonstrated.

Growing evidence suggests that many of the key signaling events that take place within the cell are initiated and/or carried out within very large protein complexes. In general, complexes efficiently bring signaling molecules in close proximity to one another and often constitute a convergence point for various signaling pathways. Regarding stress-induced apoptosis, an apoptosome is formed composed of Apaf-1, dATP, and cytochrome $c$, which subsequently recruits and processes caspase- $9,{ }^{36-38}$ which in turn activates caspase-3. Most recent studies indicate that in native lysates activated with dATP, Apaf-1 oligomerizes into both $1.4 \mathrm{MDa}$ and $700 \mathrm{kDa}$ complexes, which recruit and process caspase-9. ${ }^{26,28,34}$ However, only the latter complex activates caspases- 3 and -7 , and initial activation of these effector caspases appears to take place within the apoptosome complex. ${ }^{34,39}$ Interestingly, in AKR$2 B$ cells activation of caspase- 3 is independent of such an apoptosome composed of Apaf-1, cytochrome $c$ and caspase-9, since serum starvation does not induce the formation of this 'classical' $600 \mathrm{kD}$ apoptosome; Apaf-1, cytochrome $c$ and caspase- 9 elute most likely as dimer or probably together with other unknown proteins. These results suggest differences between the in vitro complex 
formation by cytochrome c/dATP-treatment of cytosolic extracts and the in vivo situation of apoptosis induced by serum starvation.

Here we show that in apoptosis induced by serum starvation activated caspase- 3 is recovered in three fractions during gelfiltration. Remarkably, the sizes of the complexes corroborate exactly with those reported by Cain et al. for human monocytic tumor cells (THP.1), ${ }^{26}$ i.e. 'apoptosomes' $=600 \mathrm{kD}$, 'microapoptosomes' $=250 \mathrm{kD}$ and uncomplexed caspase-3 (M.W. $80 \mathrm{kD}$ ), but the distribution of caspase- 3 in these aggregates differs strikingly. Evidently, in AKR-2B cells most of the active caspase-3 is uncomplexed, which is in contrast to the previous report by Cain et al. ${ }^{26}$ who found caspase-3 predominantly in the 'microapoptosome'-fraction. The composition of these complexes remains to be elucidated, since Cain et al. only demonstrate the coelution of caspase-3 with Apaf-1 containing complexes. Clearly in THP. 1 cells complex formation seems to be induced by an Apaf-1/caspase- 9 dependent mechanism, ${ }^{26}$ whereas in our system other pathways must be involved. Apparently in AKR-2B cells the mitochondrial pathway is not part of the serum starvation induced apoptosis because in addition to the missing 'classical' apoptosome formation the membrane potential of mitochondria is not changed ${ }^{30}$ nor is there any cytochrome $c$ efflux (data not shown).
A.

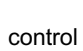

$\overbrace{30} \stackrel{669}{1}$

Caspase-3 zymogen

Caspase-3 p17

Caspase-6 zymogen

Caspase-6 p12

Caspase-9

Cytochrome c

3h starved

Caspase-3 zymogen

Caspase-3 p17

Caspase-6 zymogen

Caspase-6 p12

Caspase-9

Cytochrome c
B.

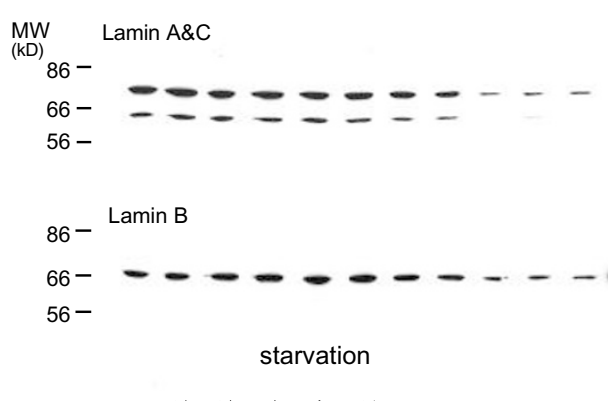

$\begin{array}{lllllllllll}0 & 1 / 4 & 1 / 2 & 3 / 4 & 1 & 1 \frac{1}{2} & 2 & 3 & 4 & 5 & 6\end{array}$

(h)

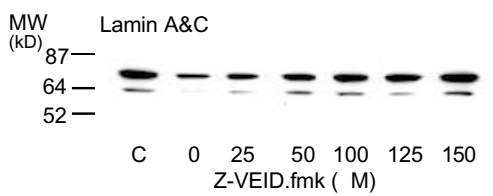

fraction
$32 \mathrm{kD}$

$17 \mathrm{kD}$

$31 \mathrm{kD}$

12 kD

$-49 \mathrm{kD}$
$-37 \mathrm{kD}$

$-25 \mathrm{kD}$

$14 \mathrm{kD}$

C.

WB: Caspase-12

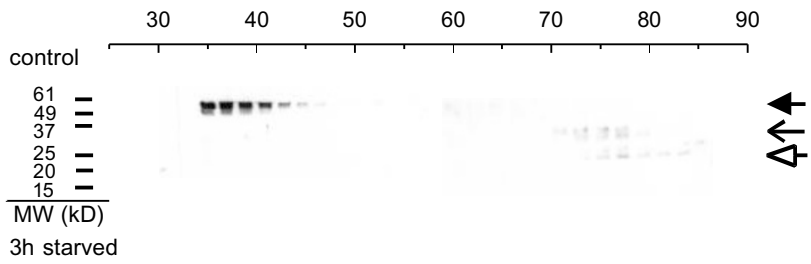

$$
\begin{gathered}
61= \\
49= \\
37= \\
25= \\
15= \\
M W(k D)
\end{gathered}
$$

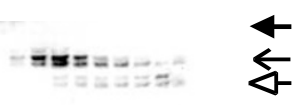

Figure 5 Analysis of complex formation by Western blotting. (A) Caspase-3 and caspase-6 are localized to different complexes after serum removal. Following gelfiltration of cytosolic extracts from non starved (upper panel) or $3 \mathrm{~h}$ starved cells (lower panel) using a sephacryl S300-HR column equal volumes of every second lyophilized fraction (see Materials and Methods) was used for Western blotting with antibodies against caspase-6 (which recognizes both the zymogene and the cleaved casp-6), caspase-3 zymogene, active caspase-3-p17, caspase-9, or cytochrome $c$. (B) Lamins are cleaved during starvation. (Upper panel) AKR2B cells were starved for the indicated times. Twenty $\mu \mathrm{g}$ of total cellular extracts was analyzed by Western blotting with antibodies directed against LaminA/C and LaminB. (Lower panel) $3 \mathrm{~h}$ starved AKR-2B cells were treated with the indicated concentrations of the caspase-inhibitor Z-VEID.fmk. C=non-starved. (C) Caspase12 is activated by serum deprivation. Every second lyophilized S300-fraction (see A) was used for Western blotting with an antibody directed against caspase-12 
A.

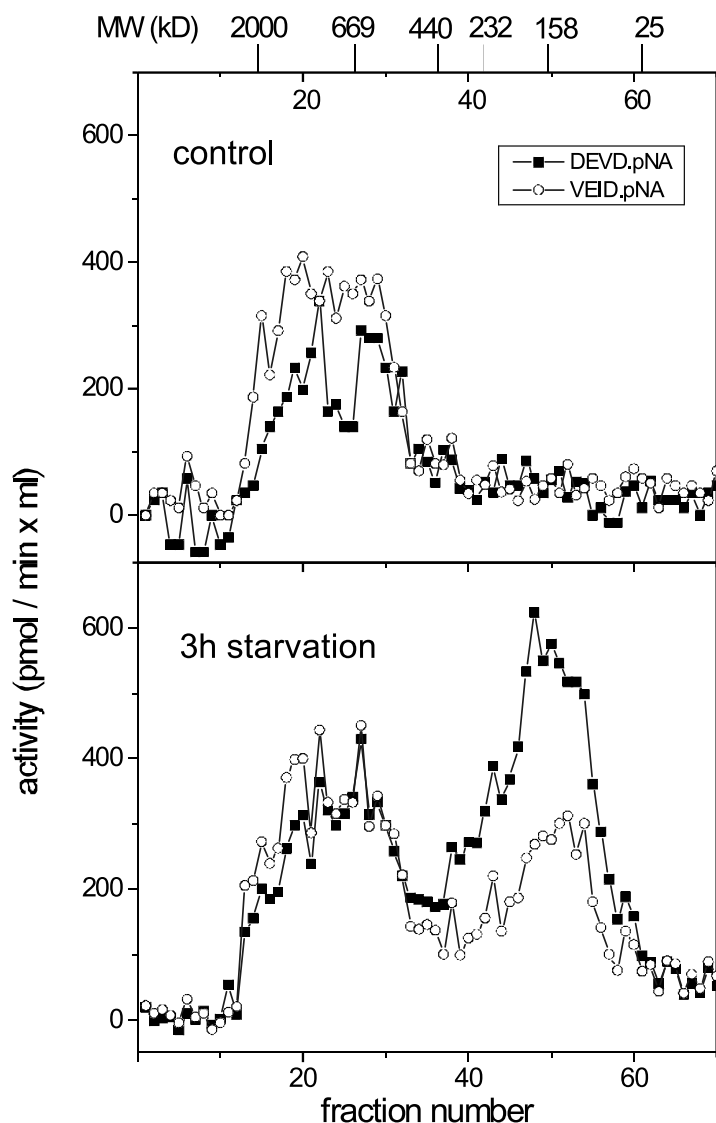

B.

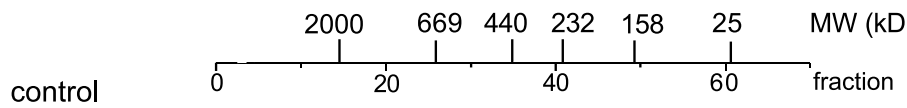

Caspase-3

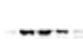

$32 \mathrm{kD}$

Caspase-3 p17

$17 \mathrm{kD}$

Caspase-12

- $49 \mathrm{kD}$

$37 \mathrm{kD}$
$25 \mathrm{kD}$

Apaf-1

$130 \mathrm{kD}$

20S-Proteasome

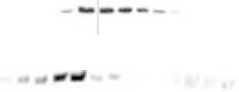

37 kD

3h starved

Caspase-3

Caspase-3 p17

Caspase-12

$17 \mathrm{kD}$

Apaf-1

20S-Proteasome

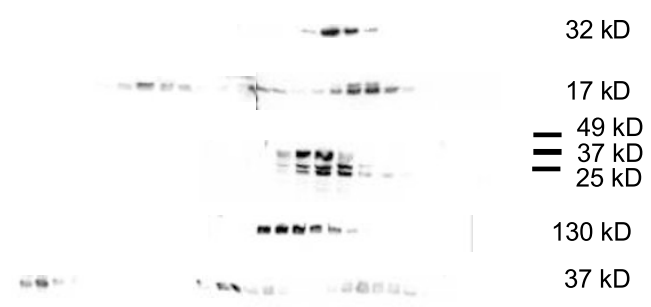

Figure 6 Separation of the high molecular weight region by Superose $6 \mathrm{HR} 10 / 30$ column. (A) Ten mg protein of cytosolic extracts from control cells (upper panel) or serum-starved cells (lower panel) was separated by gelfiltration using a Superose $6 \mathrm{HR} 10 / 30 \mathrm{column}$. Fractions of $250 \mu \mathrm{l}$ were collected. The first $5 \mathrm{ml}$ were discarded. To determine caspase activities $50 \mu \mathrm{l}$ of each fraction was incubated with $50 \mu \mathrm{M}$ of the caspase substrates (DEVD.pNA ( $\mathbf{\square}$ ) or VEID.pNA (O) ; upper panel=control, lower panel= $3 \mathrm{~h}$ starved), as described under Materials and Methods. (B) Following gelfiltration (Superose 6 column) equal volumes of every second lyophilized fraction (see Materials and Methods) was used for Western blotting with antibodies against caspase-3 zymogene, active caspase-3-p17, caspase-12, Apaf-1 or 20S-proteasome $\alpha$-subunit

Our data strongly suggests that complex formation of effector caspases might be brought about by an alternative different pathway. Induction of apoptosis might induce the distribution of active caspase-3 to these complexes. It is not clear, if these complexes activate caspase-3, because caspase-3 zymogene is only detected as free enzyme. One possibility is that caspase-3 is cleaved as free enzyme and than complexed together with other proteins and translocated to cellular compartments, where it can cleave its substrates. Besides to the $600 \mathrm{kD}$ and $250 \mathrm{kD}$ apoptosome-like complexes we describe here for the first time a new complex of $450 \mathrm{kD}$ in which activated caspase- 6 is localized. This complex is clearly separated from the complexes containing activated caspase-3.

During receptor (CD95)-mediated apoptosis, formation of the DISC is absolutely required for activation of the apical caspase-8. ${ }^{18-21}$. Activated caspase-8 in turn starts the caspase-cascade leading to the activation of caspase-3. Whether the DISC activates effector caspases during receptor-mediated apoptosis in a similar manner like the apoptosome is unknown, but such a mechanism is plausible. In any event, large complexes are apparently required for the activation of initiator caspases and may additionally activate effector caspases. In AKR-2B fibroblasts involvements of the caspase- 8 mediated pathway is excluded since overexpression of $\mathrm{CrmA}$, the viral inhibitor of caspase-8, failed to inhibit apoptosis.

The 26S-proteasome complex is important in the nonlysosomal degradation of proteins ${ }^{40}$ and is suggested to be involved in apoptosis signaling (for review see ${ }^{41}$ ). Recently the coelution of the proteasome with VEIDase/ IETDase activities was demonstrated. ${ }^{26}$ Here we provide evidence that in response to serum starvation the proteasome assembles from precursor proteasome complexes into the $\sim 2 \mathrm{MDa}$ complex, which seems to represent most likely the catalytically active 26S-proteasome complex. ${ }^{35}$ Importantly, the proteasome complexes can be clearly separated from the apoptosome (by using Superose 6 column). Cain et al. speculated that VEIDase/ 
IETDase may be uncharacterized proteolytical activities of the proteasome. ${ }^{26}$ This assumption is supported by our results that (1) the active proteasome complex of $2 \mathrm{MDa}$ coelutes with VEIDase/IETDase activities which are not inhibitable by their corresponding inhibitors and (2) the

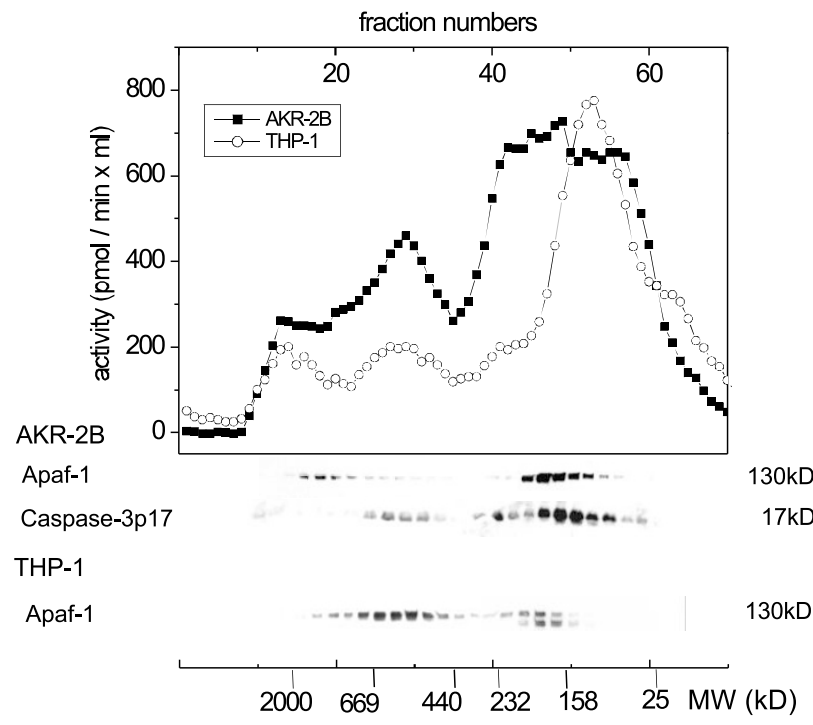

Figure 7 Reconstitution of an Apaf- 1 containing apoptosome complex in vitro by the addition of cytochrome $c, \mathrm{dATP}$ and $\mathrm{MgCl}_{2}$ to cytosolic extracts. Ten $\mathrm{mg}$ protein of cytosolic extracts from AKR-2B or THP-1 cells were incubated with $200 \mu \mathrm{g}$ cytochrome $c, 2 \mathrm{mM} \mathrm{dATP}$ and $5 \mathrm{mM} \mathrm{MgCl}_{2}$ for $1 \mathrm{~h}$ at $37^{\circ} \mathrm{C}$ and then separated by gelfiltration using a Superose $6 \mathrm{HR} 10 / 30$ column. Fractions were collected and used for DEVDase activity assays ( AKR-2B, OTHP-1) and Western blotting experiments with antibodies directed against Apaf-1 or caspase-3-p17 (see Figure 6 legend) precursor proteasome complexes, which are demonstrated not to be catalytically active ${ }^{35}$, elute in control gelfiltration experiments in fractions lackingVEIDase/IETDase activities.

Recently an additional apoptotic mechanism has been described in mouse neuronal cells which involves caspase$12 .^{27}$ Caspase-12 is localized to the ER and specifically activated by endoplasmatic stress. Serum deprivation had no effect. The activation of caspase-12 in this ER specific pathway seems to be mediated by $\mathrm{m}$-Calpain, which is sensitive to millimolar concentrations of calcium. ${ }^{42}$ In contrast to these studies, we demonstrate here the activation of caspase-12 by serum deprivation in AKR-2B fibroblasts.

In summary, activation of caspase-3 in AKR-2B fibroblasts is independent of the known major pathways, namely by caspase- 8 activation or the formation of an apoptosome containing Apaf-1, cytochrome $c$ and caspase-9. One possibility is the activation of caspase- 3 by a caspase-12 mediated pathway. Importantly, we demonstrated the distribution of activated caspase-3 and caspase-6 into different high molecular weight complexes. Further work is in progress to identify the proteins composing the apoptosome-like complexes and to elucidate the role of caspase-12 in the apoptosis after serum deprivation.

\section{Materials and Methods}

\section{Materials}

Antibodies directed against caspase-1 and -3 were supplied by Upstate Biotechnology (Biozol, Eching, Germany), caspase-2 and Apaf-1 by Transduction Laboratories (Becton Dickinson, Heidelberg,
A

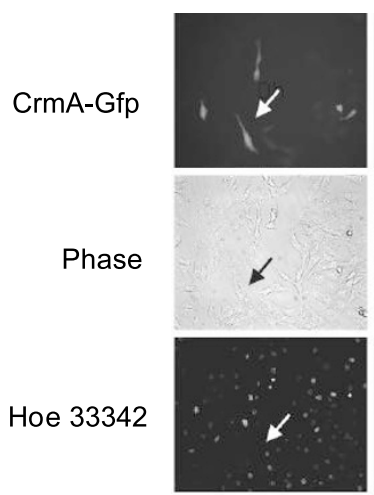

Oh

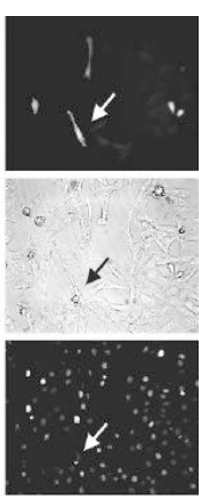

$2 \mathrm{~h}$



$3 \mathrm{~h}$
B

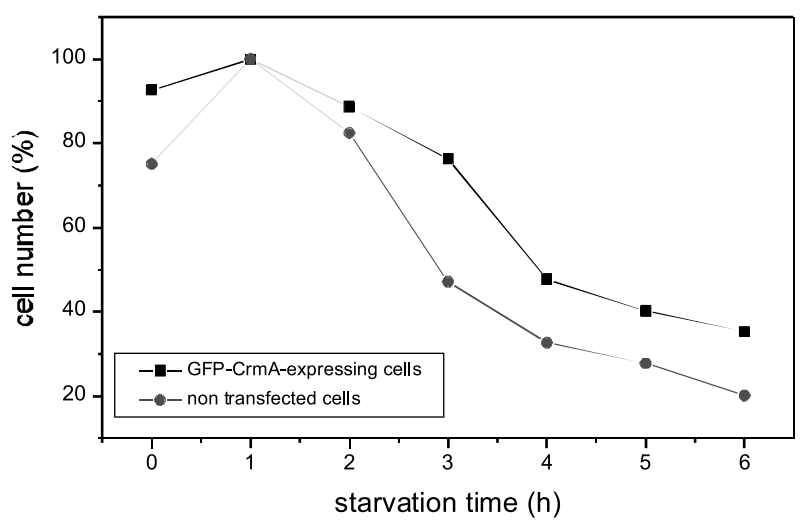

Starvation

Figure 8 Overexpression of CrmA does not prevent starvation-induced apoptosis. (A) AKR-2B cells were transfected with a fusion protein of CrmA - GFP and seeded on coverslips. After $18 \mathrm{~h}$ the coverslips were assembled in a special chamber for cultivating cells under the microscope and cells were starved $(+10 \mu \mathrm{M}$ Anisomycin) for the indicated times. Nuclei were counterstained with $1 \mu \mathrm{g} / \mathrm{ml}$ Hoe33342. Photographs were taken using the appropriate filter for green fluorescence (GFP, upper panel), or blue fluorescence (Hoe33342, lower panel), respectively or phase contrast (middle panel). The arrow shows an individual dying cell. (B) Transfection of $\mathrm{CrmA}$ cloned into pIRES expression vector was done by electroporation. After $18 \mathrm{~h}$ cells were serum depleted (in combination with $10 \mu \mathrm{M}$ Anisomycin) for the time periods indicated and then analyzed by flow cytometry (- -CrmA-GFP-expressing cells, - non transfected cells). The cell numbers are calculated as percentage of non-starved AKR-2B cells. One representative of three independent experiments is shown 
Germany), caspase-3-p17 and caspase-7 antibodies by New England Biolabs (Frankfurt, Germany), caspase- 6 and cytochrome $c$ by Pharmingen (Becton Dickinson, Heidelberg, Germany), caspase9 p10 by Santa Cruz (Heidelberg, Germany) and 20S-proteasome, $\alpha$ subunit by Calbiochem (Bad Soden, Germany). Caspase-12 antibody was kindly provided by Dr. J Yuan and Dr. T Nakagawa (Harvard Medical School, Boston, USA). Caspase substrates and inhibitors were from Bachem (Heidelberg, Germany) except of LEHD.pNA, which was from Calbiochem. $\alpha-\left({ }^{32} \mathrm{P}\right)$-dCTP was purchased from Hartmann Analytik (Braunschweig, Germany). Antibodies against lamins were a kind gift from Dr. G Krohne (Zoology, University of Würzburg). CrmA was kindly provided by Dr. DW Nicholson (Merck Frosst Center for Therapeutic Research, Quebec, Canada). THP-1 cells were provided by DSMZ (Braunschweig, Germany).

\section{Nuclease protection assay}

Five $\mu \mathrm{g}$ of total RNA, prepared according to Chomczynski and Sacchi, ${ }^{43}$ was used for nuclease protection assay Riboquant ${ }^{\mathbb{R}}$. Following manufacturer instructions (Pharmingen, Becton Dickinson, Heidelberg, Germany) the RNA was hybridized with the template set mApo-1 for mouse caspases. To detect caspase- 9 mRNA a probe was constructed by PCR using following oligonucleotide primers TGGTGGAGGTGAAGAACGAC and GAATTCAGTGCAGGCCACCTCAAAG. As template an EST-clone (Acc No: Al155222) was used. The PCR product was cloned into pcDNA3.1/V5/His-TOPO (Invitrogen, Groningen, The Netherlands) and then used as template for nuclease protection assay following manufacturer instructions.

\section{Cell culture}

Stock cultures of AKR-2B mouse fibroblasts were propagated in antibiotic-free McCoy-5A medium (Life Technologies, Eggenstein, Germany) with $5 \%$ Hyclone calf serum for less than 3 months to minimize fluctuations. Cultures were seeded at a density of $5 \times 10^{3}$ cells $/ \mathrm{cm}^{2}$ into $14.5 \mathrm{~cm}$ plastic dishes (Falcon, Becton Dickinson, Heidelberg, Germany) and grown for 5 days without medium change. To induce apoptosis cells were washed twice and further cultured in MCDB-402 medium (Life Technologies, Eggenstein, Germany).

For preparing cytosolic extract all steps were performed at $4^{\circ} \mathrm{C}$. Cells grown on $14.5 \mathrm{~cm}$ culture dishes were rinsed in $25 \mathrm{ml}$ buffer $A$ (5 mM MgCl 2 , 2 mM EGTA, 50 mM HEPES, pH 7.0), scraped with a rubber policeman and disrupted with a tight fitting Dounce homogenizator. Homogenate was clarified by centrifugation at $100000 \times g$ for $20 \mathrm{~min}$ and the supernatant was immediately used. THP-1 were cultured in accordance to the literature. ${ }^{34} 8 \times 10^{7}$ cells were harvested by centrifugation. The resulting pellet was resuspended in $3 \mathrm{ml}$ buffer $A$ and disrupted with a tight fitting Dounce homogenizator. Cytosolic extracts $(100000 \times g$ supernatant) were prepared by ultra-centrifugation (see AKR-2B).

\section{Gel electrophoresis, immunoblotting and affinity blotting}

To label caspases with the specific inhibitor YVK(-bio)D.aomk (Bachem, Heidelberg, Germany) cytosolic extracts were incubated for $30 \mathrm{~min}$ at $37^{\circ} \mathrm{C}$ with $10 \mu \mathrm{M}$ of the reagent prior diluted in buffer $\mathrm{A}$ (see above). The samples were directly used or if necessary lyophilized.

For 1-D gel electrophoresis cell lysates were prepared as described previously. ${ }^{31}$ Lyophilized fractions from ion exchange- or gel-chromatography or cytosolic extracts were diluted with SDS- sample buffer (50 mM Tris-Cl, pH 6.7, 2\% SDS) and after protein determination $2 \% 2$-mercaptoethanol was added. Twenty $\mu \mathrm{g}$ was taken for electrophoresis using $12 \%$ acrylamide gels $(30 \% / 0.8 \%(\mathrm{w} / \mathrm{w})$ acrylamide/bisacrylamide) with $0.75 \mathrm{~mm}$ thickness.

For 2-D gelelectrophoresis lyophilized samples were dissolved in IEF-buffer (8 M urea, 1\% CHAPS, 1\% DTT, 2\% ampholytes pH 3.510; Serva, Heidelberg, Germany) and incubated with Immobiline Drystrips ( $\mathrm{pH} 3-10$, linear, Amersham Pharmacia) overnight. Following manufacturer instructions bioelectric focusing was done with $14000 \mathrm{Vh}$. The strips were then loaded onto $17 \times 13 \mathrm{~cm} \mathrm{12 \%}$ polyacrylamide gels, running in parallel.

Immunoblotting was performed as described previously, ${ }^{29}$ with the exception of antibodies directed against Apaf-1, caspase-3-p17 and caspase-12, which were performed with $5 \%$ milk powder in TBS $/ 0,1 \%$ Tween-20 (25 mM Tris, pH 8, $75 \mathrm{mM} \mathrm{NaCl}, 1.25 \mathrm{mM} \mathrm{KCl}$ ) instead of $2 \%$ BSA.

Affinity blotting was performed similar to immunoblotting. The biotin residue of the affinity label YVK(-bio)D.aomk was immunostained with peroxidase-conjugated extravidin (1:2000, Sigma, Munich, Germany).

\section{Chromatography}

Chromatographic separations were carried out using an inert pump model L 6210 from Merck-Hitachi. For gelfiltration $40 \mathrm{mg}$ protein of cytosolic extract was applied onto a HiPrep Sephacryl-S-300 column $(1.6 \times 60 \mathrm{~cm}$; Amersham Pharmacia) with a flow rate of $0.8 \mathrm{ml} / \mathrm{min}$ in buffer $A$. Fractions of $1 \mathrm{ml}$ were collected. For a better resolution of high molecular weight complexes additionally $10 \mathrm{mg}$ protein of cytosolic extracts was subjected onto a Superose $6 \mathrm{HR} 10 / 30$ column (Amersham Pharmacia; flow rate $0.5 \mathrm{ml} / \mathrm{min}$ in buffer $\mathrm{A}$; fraction volume $250 \mathrm{II}$ ). Sephacryl S300 and Superose 6 HR 10/30 columns were calibrated with a gelfiltration calibration kit (Amersham Pharmacia) showing the expected resolution. To reconstitute an apoptosome complex cytosolic extracts of AKR-2B or THP-1 cells were preincubated with $200 \mu \mathrm{g}$ cytochrome c, $2 \mathrm{mM} \mathrm{dATP}$ and $5 \mathrm{mM} \mathrm{MgCl}_{2}$ (all Sigma, Munich, Germany) for $1 \mathrm{~h}$ at $37^{\circ} \mathrm{C}$ and were subsequently separated by Superose $6 \mathrm{HR}$ column. For anionic exchange chromatography $5 \mathrm{mg}$ of protein were separated on Resource $Q$ column $(0.5 \times 5 \mathrm{~cm}$, Merck, Darmstadt, Germany). A linear gradient starting from buffer $A$ to buffer $A$ containing $0.3 \mathrm{M} \mathrm{NaCl}$ was applied during $1 \mathrm{~h}$. Flow rate was $0.5 \mathrm{ml} / \mathrm{min}$ and fractions of $0.75 \mathrm{ml}$ were collected.

For Western blotting $200 \mu \mathrm{l}$ was lyophilized and taken up in $60 \mu \mathrm{l}$ SDS-sample buffer. Fifteen $\mu \mathrm{l}$ was taken for electrophoresis.

\section{Caspase activity assay}

To determine caspase activity cytosolic extract was supplemented with substrate (DEVD.pNA, VEID.pNA, IETD.pNA or LEHD.pNA), adjusted in microtiter plates to $100 \mu \mathrm{l}$ with buffer $\mathrm{A}$. For measurement of caspase activity after chromatography $100 \mu \mathrm{l}$ of a respective fraction was supplemented with $10 \mu \mathrm{l}$ of concentrated substrate. For inhibitor studies the specific inhibitors were preincubated for $10 \mathrm{~min}$ before substrate was added. The enzymatic reaction was carried out in a microtiter plate for $45 \mathrm{~min}$ at $37^{\circ} \mathrm{C}$. Absorbance was measured at $405 \mathrm{~nm}$ in a microtiter plate-reader and the specific activity was calculated using p-nitroanilide as a standard.

\section{Transfection, flow cytometric analysis and immunofluorescence}

Eighteen hours prior to transfection $4 \times 10^{6}$ AKR-2B fibroblasts were seeded into $14.5 \mathrm{~cm}$ plates. Cells were detached with trypsin and $2 \times 10^{6}$ 
cells were resuspended in hypo-osmolaric buffer $\left(0.3 \mathrm{mM} \mathrm{KH}_{2} \mathrm{PO}_{4}\right.$, $0.85 \mathrm{mM} \mathrm{K}_{2} \mathrm{HPO}_{4}, 25 \mathrm{mM}$ myo-inositol, $100 \mathrm{mOsmol}$ ). Transfection with $10 \mu \mathrm{g}$ of plasmid DNA was done using an electroporator (Eppendorf, Hamburg, Germany) with 400V, $100 \mu \mathrm{s}$, and two pulses.

For flow cytometric analyses transfected cells were grown in 6-well plates. After starvation for the indicated times cells were detached and equilibrated to $1 \times 10^{6} \mathrm{cell} / \mathrm{ml}$ in PBS. Nuclei were counterstained with $2 \mu \mathrm{g} / \mathrm{ml}$ 7-AAD and analyzed using EPICS ESP from Coulter (Beckman Coulter, Krefeld, Germany).

For time lapsed fluorescence microscopy transfected cells were grown on coverslips to subconfluency. The coverslips were mounted into an appliance for culturing cells under the microscope (Leica DM IRB, Leica, Bensheim, Germany) and were overlaid with appropriate medium. To counterstain nuclei $0.1 \mu \mathrm{g} / \mathrm{ml}$ of Hoe33342 (Sigma, München, Germany) was added. Filter N.1 and A (Leica, Bensheim, Germany) were used to monitor blue or green fluorescence, respectively. Photographs were recorded using a cooled digital camera (Kappa, Gleichen, Germany).

\section{Acknowledgements}

We would like to thank Barbara Bayer for expert technical assistance, Dr. Junying Yuan and Dr. Toshiyuki Nakagawa (Department of Cell Biology, Harvard Medical School, Boston, USA) for the caspase-12 antibody, Dr. Georg Krohne (Zoologie, University of Würzburg) for antibodies against lamins and Dr. DW Nicholson (Department of Biochemistry and Molecular Biology, Merck Frosst Center, Quebec, Canada) for CrmA cDNA.

\section{References}

1. Susin SA, Zamzami N, Castedo M, Daugas E, Wang HG, Geley S, Fassy F, Reed JC and Kroemer G (1997) The central executioner of apoptosis: multiple connections between protease activation and mitochondria in Fas/APO-1/ CD95- and ceramide-induced apoptosis. J. Exp. Med. 186: 25-37

2. Barinaga M (1996) Forging a path to cell death. Science 273: $735-737$

3. Bortner CD, Oldenburg NBE and Cidlowski JA (1995) The role of DNA fragmentation in apoptosis. Trends. Cell. Biol. 5: 21-26

4. Kumar S (1995) ICE-like proteases in apoptosis. Trends. Biochem. Sci. 20:198202

5. McConkey DJ and Orrenius S (1994) Signal transduction pathways to apoptosis. Trends. Cell. Biol. 4: 370-375

6. Martin SJ, Green DR and Cotter TG (1994) Dicing with death: dissecting the components of the apoptosis machinery. Tibs. 19: 26-30

7. Osborne B and Schwartz LM (1994) Essential genes that regulate apoptosis. Trends. Cell. Biol. 4: 394-399

8. Steller H (1995) Mechanisms and genes of cellular suicide. Science 267: $1445-$ 1449

9. Whyte M (1996) ICE/CED-3 proteases in apoptosis. Trends. Cell. Biol. 6: 245248

10. Fraser A and Evan G (1996) A license to kill. Cell 85: 781-784

11. Gajewski TF and Thompson CB (1996) Apoptosis meets signal transduction: elimination of a BAD influence. Cell 87: 589-592

12. van de Craen M, Vandenabeele $P$, Declerq W, van den Brande I, van Loo G Molemans F, Schotte P, van Criekinge W, Beyaert R and Fiers W (1997) Characterization of seven murine caspase familiy members. FEBS lett. 403:61 69

13. Nicholson DW and Thornberry NA (1997) Caspases: killer proteases. Trends Biol.Sci. 22: 299-306

14. Martins LM and Earnshaw WC (1997) Apoptosis: alive and kicking in 1997. Trends. Cell. Biol. 7: 111-114

15. Thornberry NA and Lazebnik Y (1998) Caspases: enemies within. Science 281 $1312-1316$
16. Nicholson DW (1999) Caspase structure, proteolytic substrates, and function during apoptotic cell death. Cell Death Diff. 6: 1028-1042

17. Porter AG and Jänicke RU (1999) Emerging roles of caspase-3 in apoptosis. Cell Death Diff. 6: 99-104

18. Ashkenazi A and Dixit VM (1998) Death receptors: signaling and modulation. Science 281: 1305-1308

19. Kumar S (1999) Mechanisms mediating caspase activation in cell death. Cell Death Diff. 6: 1060-1066

20. Slee EA, Adrain C and Martin SM (1999) Serial killers: ordering caspase activation events in apoptosis. Cell Death Diff. 6: 1067-1074

21. Thornberry NA (1999) Caspases: A decade of death research. Cell Death Diff. 6 : $1023-1027$

22. Green DR and Reed JC (1998) Mitochondria and apoptosis. Science 281: $1309-1312$

23. Cecconi F (1999) Apaf1 and the apoptotic machinery. Cell Death Diff. 6: 1087 1098

24. Susin SA, Lorenzo HK, Zamzami N, Marzo I, Snow BE, Brothers GM, Mangion J, Jacotot E, Costantini P, Loeffler M, Larochette N, Goodlett DR, Aebersold R, Siderovski DP, Penninger JM and Kroemer G (1999) Molecular characterization of mitochondrial apoptosis-inducing factor. Nature 387: 441-446

25. Lorenzo HK, Susin SA, Penninger J and Kroemer G (1999) Apoptosis inducing factor (AIF): a phylogenetically old, caspase-independent effector of cell death. Cell Death Diff. 6: 516-524

26. Cain K, Brown DG, Langlais C and Cohen GM (1999) Caspase Activation Involves the Formation of the Aposome, a Large ( $700 \mathrm{kDa})$ Caspaseactivating Complex. J. Biol. Chem. 274: 22686-22692

27. Nakagawa T, Zhu H, Morishima N, Li E, Xu J, Yankner BA and Yuan J (2000) Caspase-12 mediates endoplasmic-reticulum-specific apoptosis and cytotoxicity by amyloid- $\beta$. Nature 403: $98-103$

28. Bratton SB, MacFarlane M, Cain K and Cohen GM (2000) Protein complexes activate distinct caspase cascades in death receptor and stress-induced apoptosis. Exp. Cell Res. 256: 27-33

29. Simm A, Hoppe V, Gazit A and Hoppe J (1994) Platelet-derived growth factor isoforms prevent cell death during starvation of AKR-2B fibroblasts. J. Cell. Physiol. 160: 295-302

30. Simm A, Bertsch G, Frank H, Zimmermann U and Hoppe J (1997) Cell death of AKR-2B fibroblasts after serum removal: a process between apoptosis and necrosis. J. Cell Sci. 110: 819-828

31. Schäfer R, Karbach D and Hoppe J (1998) Multiple intracellular pathways interfere with the activation of a CPP32-like protease induced by serum deprivation of AKR-2B cells. Exp. Cell. Res. 240: 28-39

32. Hoppe J, Schafer R, Hoppe V and Sachinidis A (1999) ATP and adenosine prevent via different pathways the activation of caspases in apoptotic AKR-2B fibroblasts. Cell Death Differ. 6: 546-556

33. Faleiro L, Kobayashi R, Fearnhed $\mathrm{H}$ and Lazebnik $Y$ (1997) Multiple species of CPP32 and Mch2 are the major active caspases present in apoptotic cells. EMBO J. $16: 2271-2281$

34. Cain K, Bratton SB, Langlais C, Walker G, Brown DG, Sun XM and Cohen GM (2000) Apaf-1 oligomerizes into biologically active $\sim 700-\mathrm{kDa}$ and inactive $\sim 1.4-$ MDa apoptosome complexes. J. Biol. Chem. 275: 6067-6070

35. Nandi D, Woodward E, Ginsburg DB and Monaco JJ (1997) Intermediates in the formation of mouse 20S proteasomes: implications for the assembly of precursor beta subunits. EMBO J. 16: $5363-5375$

36. Zou H, Henzel WJ, Liu X, Lutschg A and Wang X (1997) Apaf-1, a human protein homologous to $\mathrm{C}$. elegans CED-4, participates in cytochrome $\mathrm{C}$ dependent activation of caspase-3. Cell 90: 405-413

37. Zou H, Li Y, Liu X and Wang X (1999) An APAF-1cytochrome c multimeric complex Is a functional apoptosome that activates procaspase-9. J. Biol. Chem. 274: $11549-11556$

38. Saleh A, Srinivasula SM, Acharya S, Fishel R and Alnemri ES (1999) Cytochrome $c$ and dATP-mediated oligomerization of Apaf-1 is a prerequisite for procaspase-9 activation. J. Biol. Chem. 274: 17941-17945

39. Rodriguez $\mathrm{J}$ and Lazebnik $\mathrm{Y}$ (1999) Caspase-9 and Apaf-1 form an active holoenzyme. Gen. Dev. 3: 3179-3184

40. Coux O, Tanaka K and Goldberg AL (1996) Structure and functions of the $20 \mathrm{~S}$ and $26 \mathrm{~S}$ proteasomes. Annu. Rev. Biochem. 65: 801-847 
41. Orlowski RZ (1999) The role of the ubiquitin-proteasome pathway in apoptosis. Cell Death Diff. 6: 303-313

42. Nakagawa $T$ and Yuan $J(2000)$ Cross-talk between two cysteine protease families: activation of caspase-12 by calpain in apoptosis. J. Cell Biol. 150: $887-$ 894
43. Chomczynski Pand SacchiN (1987) Single-step method of RNA isolation by acid guanidinium thiocyanate-phenol-chloroform extraction. Anal. Biochem. 162: $156-159$

44. Dixon MW and Webb EC (1953) Biochem. J. 55: 170-117 